\title{
Intracellular Conformations of Human Telomeric Quadruplexes Studied by Electron Paramagnetic Resonance Spectroscopy
}

\author{
Mykhailo Azarkh, Vijay Singh, Oliver Okle, Daniel R. Dietrich, Jörg S. Hartig, ${ }^{*}$ and Malte Drescher*[a]
}

The native structure of biological macromolecules in living cells has remained largely unexplored because of the lack of suitable methods. Recently, in-cell electron paramagnetic resonance (in-cell EPR), in particular in-cell double electron electron resonance (in-cell DEER), has been introduced for model systems. ${ }^{[1-3]}$ Previous reports on in vitro DEER applications to study DNA deal mostly with samples of double helical structure. ${ }^{[4-7]}$ Herein, for the first time, in-cell DEER was successfully employed to study the formation of human telomeric (HT) Gquadruplexes (Figure 1) upon microinjection of an unfolded DNA sequence (Figure $1 \mathrm{~b}$ ) into living cells. G-quadruplexes have been suspected to play important roles in cellular processes but their existence in cells is difficult to ascertain. Indeed, induction of quadruplexes at the telomere was shown to interfere with telomere integrity and to inhibit proliferation of cancer cells. ${ }^{[8,9]}$
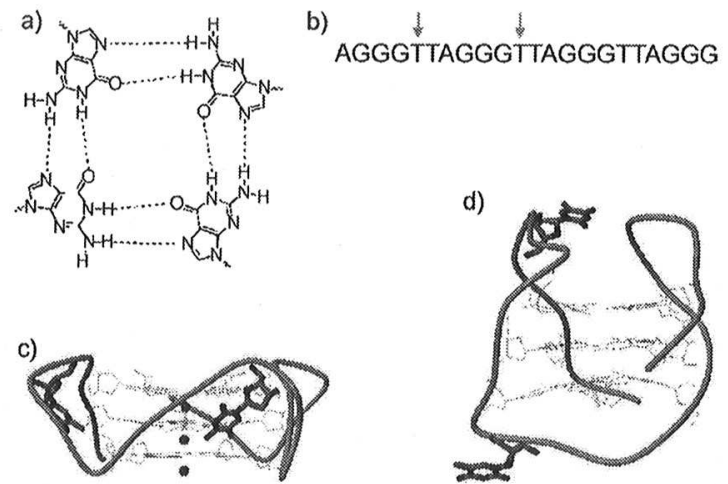

Figure 1. a) G tetrad. b) HT DNA sequence used for microinjection: the arrows highlight the nitroxide spin label positions. $G$ quadruplex conforma tions for $\mathrm{d}\left[\mathrm{AGGG}\left(\mathrm{TTAGGG}_{3}\right]\right.$ ]: c) parallel propeller crystallized from $\mathrm{K}^{+}$solu tion (PDB code: $1 \mathrm{KF} 1$ ), the full circles represent $\mathrm{K}^{+}$ions; $\mathrm{d}$ ) antiparallel basket in $\mathrm{Na}^{+}$solution (PDB code: 143D). The corresponding intramolecular label distances as estimated from the PDB are $1.7 \mathrm{~nm}$ (c) and $2.9 \mathrm{~nm}$ (d).

[a] M. Azarkh, V. Singh, ${ }^{+}$O. Okle, Prof. Dr. D. R. Dietrich, Prof. Dr. J. S. Hartig, Dr. M. Drescher

Department of Chemistry

Konstanz Research School Chemical Biology (KoRS CB)

and Zukunftskolleg, University of Konstanz

78457 Konstanz (Germany)

Fax: (+ 49) 7531883139

Email:joerg.hartig@uni konstanz.de malte.drescher@uni konstanz.de

$\left.{ }^{+}\right]$Current address:

Department of Chemistry, Stanford University

Stanford, CA 94305 (USA)

Supporting information for this article is available on the WWW under http://dx.doi.org/10.1002/cphc.201100980.
G-quadruplexes show a high degree of topological polymorphism, ${ }^{[10]}$ and there is evidence of the co-existence of different conformations under physiological conditions. ${ }^{[11-13]}$ The $\mathrm{HT}$ sequence $\mathrm{d}\left[\mathrm{AGGG}(\mathrm{TTAGGG})_{3}\right]$ has been shown to exist in a 1:1 mixture of parallel propeller and antiparallel basket conformations (Figure $1 c, d$ ) in $\mathrm{K}^{+}$solution. ${ }^{[13]}$ Potassium is the most abundant metal ion in cells (with concentrations above $100 \mathrm{~mm}$ ), and in addition, concentrations as small as $1 \mathrm{mM} \mathrm{K}^{+}$ can determine the folding of a $\mathrm{K}^{+}$-dependent fold of the HT structure even in the presence of excess $(100 \mathrm{~mm}) \mathrm{Na}^{+} \cdot{ }^{[14]}$ In addition to the importance of metal ions, proteins interacting with quadruplexes are also likely to influence the stability and the type of the quadruplex within cells (see below). NMR spectra acquired in cellular extracts suggest that telomeric repeats possibly co-exist as an equilibrium mixture of different topologies; however, the low resolutions of NMR and in-cell NMR do not permit structural interpretation. ${ }^{[15,16]}$

Herein, we describe long-range distance measurements on the HT DNA repeat utilizing in-cell DEER, which is an EPR technique for determining distance distributions between spin labels in cellulo by measuring their dipole-dipole interaction. ${ }^{[17,18]}$ Since EPR only detects unpaired electron spins, no background from diamagnetic molecules is detected; and low concentrations compared to in-cell NMR spectroscopy can be used due to the higher sensitivity per spin of EPR.

The HT sequence $d\left[\mathrm{AGGG}(T \mathrm{TAGGG})_{3}\right]$ was synthesized and spin-labeled with 2,2,5,5-tetramethylpyrrolinyl- $\mathrm{N}$-oxyl-3-acetylene (TPA). ${ }^{[19]}$ HT DNA was injected into the animal hemisphere cytoplasm of stage $\mathrm{VI}$ oocytes of Xenopus laevis (X. Laevis), where nucleus-like conditions preside. ${ }^{[20]}$

For distance measurements, the HT sequence was labeled in the trinucleotide loop region at positions 5 and 11 (Figure $1 \mathrm{~b}$ ). Labeling at these particular positions does not disturb G-quadruplex structures and allows their distinction (see the Supporting Information). The distances between the spin labels can be estimated from the 5-methyl carbon atoms of the labeled positions taken from the PDB structures and resulting in $1.7 \mathrm{~nm}$ for the parallel propeller quadruplex (PDB $1 \mathrm{KF}$, Figure $1 \mathrm{C})^{[21]}$ and $2.9 \mathrm{~nm}$ for the antiparallel basket quadruplex (PDB: 143D, Figure $1 \mathrm{~d}) .{ }^{[22]}$ These values are in good agreement with experimental distance constraints obtained in buffered solution: $1.8 \pm 0.2 \mathrm{~nm}$ for the parallel propeller quadruplex and $3.0 \pm$ $0.1 \mathrm{~nm}$ for the antiparallel basket quadruplex. ${ }^{[13]}$ Details of synthesis, spin labeling, biophysical characterization, sample preparation, experiments, and data analysis are provided in the Supporting Information.

Microinjection of doubly spin-labeled HT DNA into cells was carried out using a salt-free stock solution where no quadruplex folding was observed (see Supporting Information, Fig- 
ure S2). Quadruplex folding in cellulo is possibly much slower than in buffered solution, where folding is completed within 2 min (Figures S9 and S10 of the Supporting Information). On the other hand, TPA attached to HT DNA had a half-life of $29 \pm$ $7 \mathrm{~min}$ (Figure 2). Consequently, an incubation time of $15 \mathrm{~min}$ was chosen to allow formation and equilibration of quadruplex structures while circumventing quenching of most of the nitroxide spin labels due to reduction. ${ }^{[23]}$ After incubation, the samples were shock-frozen to trap the adopted conformations for in-cell distance measurements.

While the concentration of the HT DNA stock solution is rather high $(4 \mathrm{~mm})$, its effective final intracellular concentration due to diffusion inside oocytes is approximately $200 \mu \mathrm{m}$. Due to nitroxide reduction inherent to in-cell DEER, the signal-to-

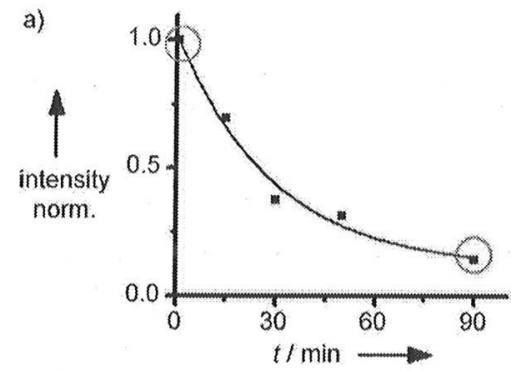

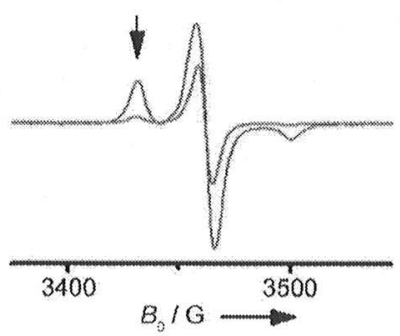

Figure 2. Reduction of single spin labeled HT DNA inside $X$. laevis oocytes. a) Time dependent decay of the signal intensity in the nitroxide spectrum upon incubation at room temperature. The green and red circles denote the points for which representative cW EPR spectra, measured at $T=120 \mathrm{~K}$ and a microwave frequency of $9.5 \mathrm{GHz}$, are shown in (b): $30 \mathrm{sec}$ (green) and $90 \mathrm{~min}$ (red) after injection. The error bars are smaller than the symbol size. For details, see the Supporting Information.

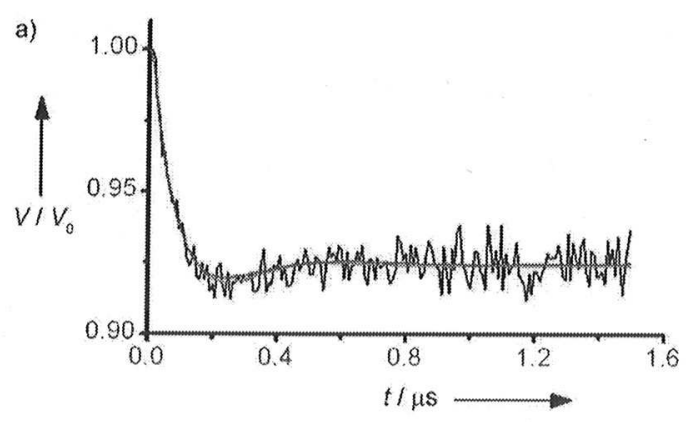

b)

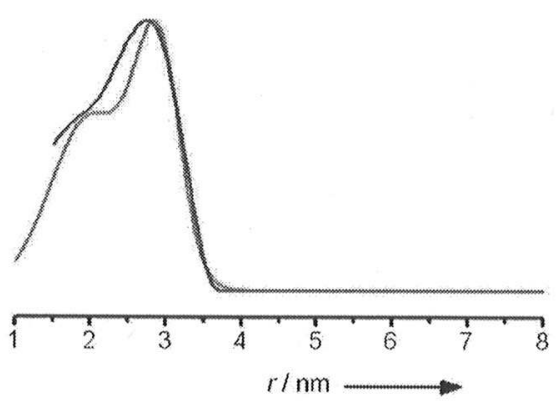

Figure 3. In cell distance measurement of spin labeled HT DNA by DEER in $X$ band at $T=45 \mathrm{~K}$, total acquisition time $24 \mathrm{~h}$. a) Experimental DEER curve after background correction (black) fitted with the two Gauss curve model (red) and model free TR (blue). b) Calculated distance distributions: two Gauss curve model (red) and TR (blue), artifacts above $4.5 \mathrm{~nm}$ are sup pressed (see Supporting Information). noise ratio of the DEER curve (Figure $3 a$ ) is low. Therefore, a systematic analysis of the influence of all steps in the data post-processing process was performed (see Supporting Information). Finally, model-free Tikhonov regularization (TR) ${ }^{[24]}$ of the DEER curve (Figure 3 a) resulted in a distance distribution (Figure $3 \mathrm{~b}$, blue) with two distinct maxima (see Supporting Information for a statistical analysis). Accordingly, the experimental data were also fitted by a model consisting of two Gaussians curves (Figure 3, Table 1) centred at 2.0 and $2.9 \mathrm{~nm}$, respectively, with $55 \%$ contribution from the second Gaussian. The width of this distribution is a resultant of the flexibility of the spin label attached to the trinucleotide loops. ${ }^{[9]}$ While other quadruplex topologies, including intermolecular quadruplexes, can be excluded (Supporting Information), the maxima in the distance distribution were assigned to two conformations, namely the parallel propeller and the antiparallel basket form, respectively. Hence, the observation of the 1:1 coexistence of both conformations reported previously for $\mathrm{K}^{+}$buffer also holds true in cellulo.

To perform time-dependent DEER measurements, a single sample of HT DNA stock solution was added to an extract of $X$. laevis oocytes. To save valuable

\begin{tabular}{|c|c|c|c|c|c|}
\hline Experiment & $\begin{array}{l}\text { Distance } \\
\text { constraint } \\
r_{1}[\mathrm{~nm}]\end{array}$ & $\begin{array}{l}\text { Width of } \\
1 \mathrm{st} \\
\text { Gaussian } \\
\sigma_{1}[\mathrm{~nm}]\end{array}$ & $\begin{array}{l}\text { Distance } \\
\text { constraint } \\
r_{2}[\mathrm{~nm}]\end{array}$ & $\begin{array}{l}\text { Width of } \\
\text { 2nd } \\
\text { Gaussian } \\
\sigma_{2}[\mathrm{~nm}]\end{array}$ & $\begin{array}{l}\text { Fraction of } \\
\text { distance } \\
\text { constraint } \\
r_{1}\end{array}$ \\
\hline $\begin{array}{l}\text { In extract } \\
(30 \mathrm{sec})^{[\mathrm{a}]}\end{array}$ & $2.0^{[b]}$ & 0.4 & $2.9^{[b]}$ & 0.6 & $21 \%$ \\
\hline $\begin{array}{l}\text { In extract } \\
(12 \mathrm{~min})^{[a]}\end{array}$ & $2.0^{[\mathrm{b}]}$ & 0.5 & $2.9^{[b]}$ & 0.4 & $37 \%$ \\
\hline $\begin{array}{l}\text { In extract } \\
(20 \mathrm{~min})^{[a]}\end{array}$ & $2.0^{[\mathrm{b}]}$ & 0.6 & $2.9^{[b]}$ & 0.4 & $49 \%$ \\
\hline In cell ${ }^{[c]}$ & $\begin{array}{l}2.0 \\
( \pm 0.1)\end{array}$ & $\begin{array}{l}0.7 \\
( \pm 0.1)\end{array}$ & $\begin{array}{l}2.9 \\
( \pm 0.1)\end{array}$ & $\begin{array}{l}0.4 \\
( \pm 0.1)\end{array}$ & $\begin{array}{l}45 \% \\
( \pm 4 \%)\end{array}$ \\
\hline
\end{tabular}

sample material and obtain directly comparable distance distributions, the sample was thawed after each DEER experiment, incubated at room temperature, and re-frozen for the next inextract DEER experiment.

The observed reduced modulation depth of the DEER curves after background correction with increasing incubation time (Figure 4 a) reflects spin-label reduction which did not allow for longer incubation times. To enable monitoring of conformational changes, distance distribution were obtained by modelfree TR (Figure $4 \mathrm{~b}$ ). These distance distributions, when fitted 


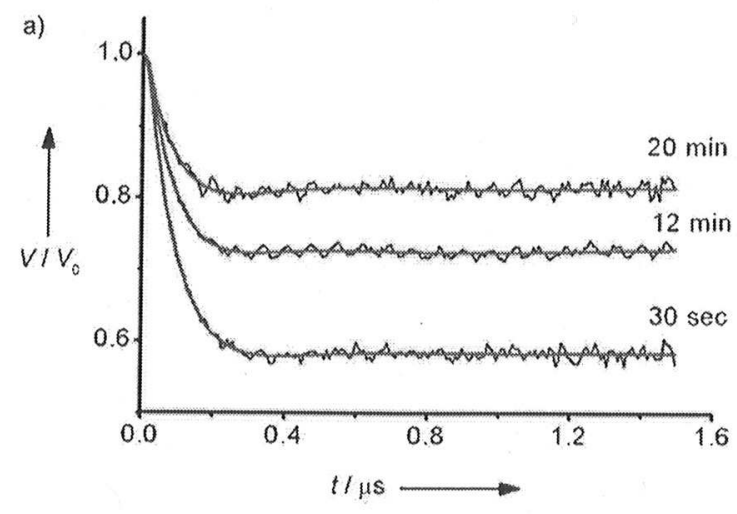

b)

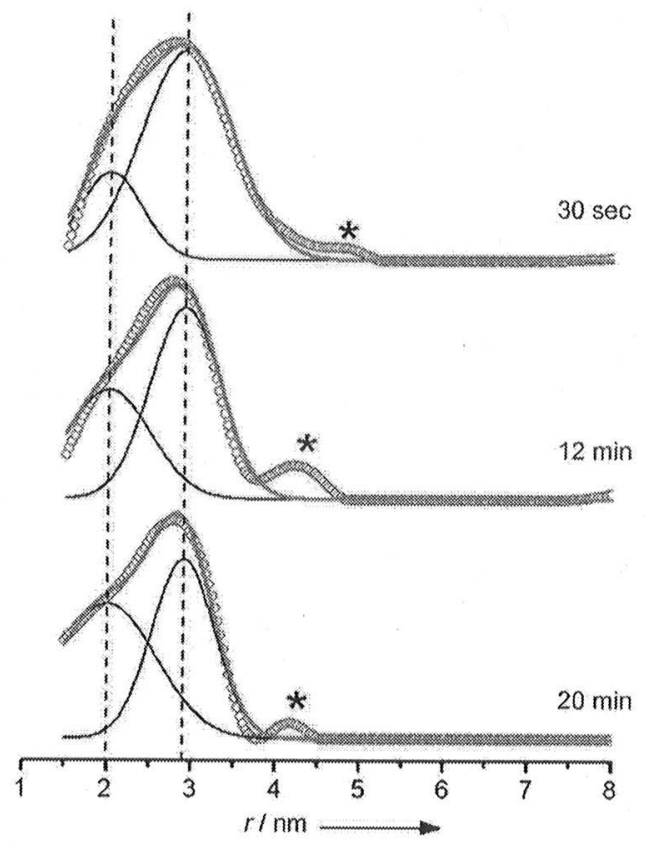

Figure 4. In extract distance measurements of spin labeled HT DNA by DEER in $\mathrm{X}$ band at $T=45 \mathrm{~K}$. a) Experimental background corrected DEER curves for different incubation times (black) fitted with TR (blue). b) TR calculated dis tance distributions (blue circles), the red solid lines represent a superposition of two separate Gaussian curves (black) whose maxima are fixed at 2.0 and $2.9 \mathrm{~nm}$ (vertical black dotted lines). The distance distribution curves from TR are normalized to the area under the curve. The asterisks mark artifacts in distance distributions due to TR. ${ }^{(22)}$

with two Gaussians, exhibit maxima at $2.00 \pm 0.05$ and $2.9 \pm$ $0.05 \mathrm{~nm}$. To parameterize changes of inter-spin distances in the cell extract and, accordingly, to evaluate in-cell findings, the maxima of the two Gaussians were kept constant at 2.0 and $2.9 \mathrm{~nm}$, and only their width and ratio were varied. Figure $4 \mathrm{~b}$ demonstrates the conformational change from an undefined, open conformation observed in salt-free buffer (Figure S8, Supporting Information) to the mixture of parallel propeller and antiparallel basket conformation detected in the cell extract. The rather slow increase of the fraction assigned to the parallel propeller conformation (peak at $2.0 \mathrm{~nm}$ ) on a minute time scale suggests that the conformation initially adopted by a G- quadruplex injected into cells may not be the one that is adopted in the equilibrium state, as already suggested. ${ }^{[25]}$ After 20 min incubation, the DEER data indicates that the fraction of the parallel propeller form reaches approximately $50 \%$ (Table 1).

In conclusion, we applied in-cell EPR to investigate human telomeric quadruplex formation in the cellular environment of $X$. laevis oocytes. Moreover, time-dependent in-extract distance measurements allowed monitoring the G-quadruplex folding, thus supporting the in cellulo findings. With the current study, novel in-cell DEER has been shown to provide information on non-canonical DNA structures folding in living cells, which has hitherto been unachievable.

\section{Acknowledgements}

This work was financially supported by the DFG (DR 743/2-1), the Zukunftskolleg Konstanz, and the Young Scholar Fund Konstanz within the Exzellenzinitiative.

Keywords: biophysics . DNA . EPR spectroscopy - in-cell DEER - quadruplexes

[1] R. Igarashi, T. Sakai, H. Hara, T. Tenno, T. Tanaka, H. Nochio, M. Shirakawa, J. Am. Chem. Soc. 2010, 132, 82288229.

[2] I. Krstic, R. Hänsel, O. Romainczyk, J. W. Engels, V. Dötsch, T. F. Prisner, Angew. Chem. 2011, 123, 5176 5180; Angew. Chem. Int. Ed. 2011, 50, 50705074.

[3] M. Azarkh, O. Okle, V. Singh, I. T. Seemann, J. S. Hartig, D. R. Dietrich, M. Drescher, ChemBioChem 2011, 12, 19921995.

[4] O. Schiemann, N. Piton, Y. Mu, G. Stock, J. W. Engels, T. F. Prisner, J. Am. Chem. Soc. 2004, 126, 57225729.

[5] Q. Cai, A. K. Kusnetzow, W. L. Hubbell, I. S. Haworth, G. P. C. Gacho, N. V. Eps, K. Hideg, E. J. Chambers, P. Z. Qin, Nucl. Acids Res. 2006, 34, 4722 4730.

[6] R. Ward, D. J. Keeble, H. El Mkami, D. G. Norman, ChemBioChem 2001, 8, 19571964.

[7] A. Marko, V. Denysenkov, D. Margraf, P. Cekan, O. Schiemann, S. Th. Si gurdsson, T. F. Prisner, J. Am. Chem. Soc. 2011, 133, 1337513379.

[8] X. Yan, Chem. Soc. Rev. 2011, 40, 27192740.

[9] S. Neidle, FEBS J. 2010, 277, 11181125.

[10] S. Burge, G. N. Parkinson, P. Hazel, A. K. Todd, S. Neidle, Nucleic Acids Res. 2006, 34, 54025415.

[11] P. Hazel, J. Huppert, S. Balasubramanian, S. Neidle, J. Am. Chem. SoC 2004, 126, 1640516415.

[12] L. Ying, J .J. Green, H. Li, D. Klenerman, S. Balasubramanian, Proc. Natl. Acad. Sci. USA 2003, 100, 1462914634.

[13] V. Singh, M. Azarkh, T. E. Exner, J. S. Hartig, M. Drescher, Angew. Chem 2009, 121, 9908 9910; Angew. Chem. Int. Ed. 2009, 48, 97289730.

[14] A. Ambrus, D. Chen, J. Dai, T. Bialis, R. A. Jones, D. Yang, Nucleic Acids Res. 2006, 34, 27232735.

[15] R. Hänsel. F. Löhr, S. Foldynova Trantirkova, E. Bamberg, L. Trantirek, V. Dötsch, Nucleic Acids Res. 2011, 39, 57685775.

[16] R. Hänsel, S. Foldynova Trantirkova, F. Löhr, J. Buck, E. Bongartz, E. Bam berg, H. Schwalbe, V. Dötsch, L. Trantirek, J. Am. Chem. Soc. 2009, 131, 1576115768.

[17] A. D. Milov, A. B. Ponomarev, Y. D. Tsvetkov, Chem. Phys. Lett. 1984, 110, 6772.

[18] M. Pannier, S. Veit, A. Godt, G. Jeschke, H. W. Spiess, J. Magn. Reson. $2000,142,331340$

[19] A. Spaltenstein, B. H. Robinson, P. B. Hopkins, Biochemistry 1989, 28, 94849495.

[20] K. Shiokawa, K. Tashiro, K. Yamana, M. Sameshima, Mol. Cell. Differ. Cell. Differ. 1987, 20, 253261. 
[21] G. N. Parkinson, M. P. H. Lee, S. Neidle, Nature 2002, 417, 876880.

[22] Y. Wang, D. J. Patel, Structure 1993, 1, 263282.

[23] M. Azarkh, O. Okle, D. R. Dietrich, M. Drescher, J. Magn. Reson. 2011 $212,450454$.

[24] 'Y. M. Chiang, P. P. Borbat, J. H. Freed, J. Magn. Reson. 2005, 172, 279 295.

[25] Y. Xue, J. q. Liu, K. w. Zheng, Z. y. Kan, Y. h. Hao, Z. Tan, Angew. Chem 2011, 123, 8196 8200; Angew. Chem. Int. Ed. 2011, 50, 80468050.
[26] G. Jeschke, V. Chechik, P. Ionita, A. Godt, H. Zimmermann, J. Banham, C. Timmel, D. Hilger, H. Jung, Appl. Magn. Reson. 2006, 30, 473498. 